\title{
Notes on the cheek region of the Late Jurassic theropod dinosaur Allosaurus
}

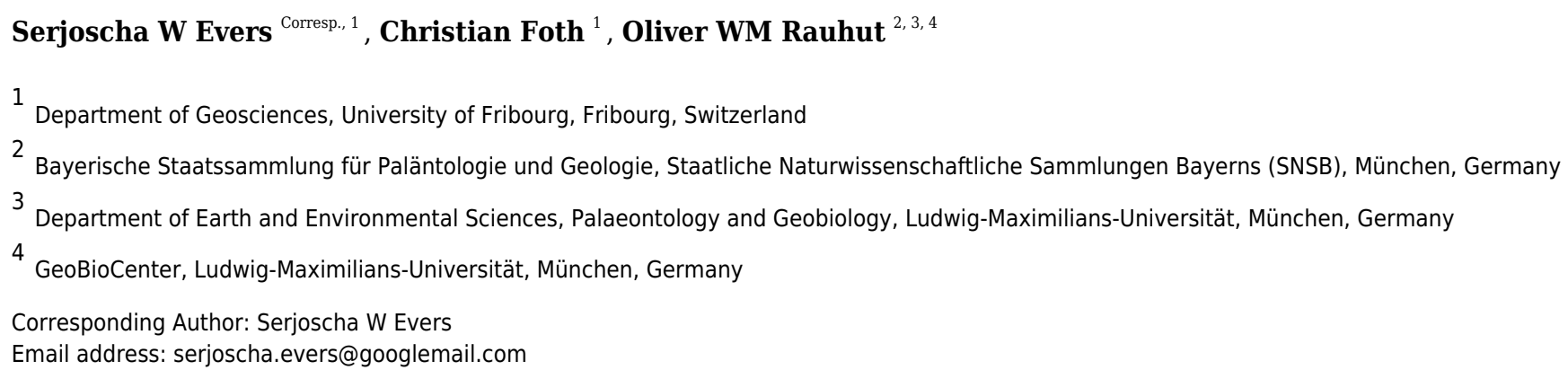

Allosaurus, from the Late Jurassic of North America and Europe, is a model taxon for Jurassic basal tetanuran theropod dinosaurs. It has achieved an almost iconic status due to its early discovery in the late, $19^{\text {th }}$ century, and due to the abundance of material from the Morrison Formation of the western U.S.A., making Allosaurus one of the best-known theropod taxa. Despite this, various aspects of the cranial anatomy of Allosaurus are surprisingly poorly understood. Here, we discuss the osteology of the cheek region, comprised by the jugal, maxilla, and lacrimal. This region of the skull is of importance for Allosaurus taxonomy and phylogeny, particularly because Allosaurus has traditionally been reconstructed with an unusual cheek configuration, and because the European species Allosaurus europaeus has been said to be different from North American material in the configuration of these bones. Based on re-examination of articulated and disarticulated material from a number of repositories, we show that the jugal participates in the antorbital fenestra, contradicting the common interpretation. The jugal laterally overlies the lacrimal, and forms an extended antorbital fossa with this bone. Furthermore, we document previously unrecorded pneumatic features of the jugal of Allosaurus. 


\section{Notes on the cheek region of the Late Jurassic 2 theropod dinosaur Allosaurus}

3

4 Serjoscha W. Evers ${ }^{1}$, Christian Foth ${ }^{1}$, Oliver W. M. Rauhut ${ }^{2,3,4}$ 5

6 'Department of Geosciences, University of Fribourg, Chemin du Musée 6, CH-1700 Fribourg, 7 Switzerland;

$8 \quad{ }^{2}$ Staatliche naturwissenschaftliche Sammlungen Bayerns (SNSB), Bayerische Staatssammlung

9 für Paläontologie und Geologie, Richard-Wagner-Str. 10, D-80333 München, Germany;

$10{ }^{3}$ Department of Earth and Environmental Sciences, Palaeontology and Geobiology, Ludwig-

11 Maximilians-Universität, Richard-Wagner-Str. 10, D-80333 München, Germany;

$12{ }^{4}$ GeoBioCenter, Ludwig-Maximilians-Universität, Richard-Wagner-Str. 10, D-80333 München, 13 Germany.

15 Corresponding author:

16 Serjoscha Evers

17 Department of Geosciences, University of Fribourg, Chemin du Musée 4, 1700 Fribourg,

18 Switzerland

19 Email address: serjoscha.evers@googlemail.com 


\section{Abstract}

23 Allosaurus, from the Late Jurassic of North America and Europe, is a model taxon for Jurassic

24 basal tetanuran theropod dinosaurs. It has achieved an almost iconic status due to its early

25 discovery in the late, $19^{\text {th }}$ century, and due to the abundance of material from the Morrison

26 Formation of the western U.S.A., making Allosaurus one of the best-known theropod taxa.

27 Despite this, various aspects of the cranial anatomy of Allosaurus are surprisingly poorly understood. Here, we discuss the osteology of the cheek region, comprised by the jugal, maxilla, and lacrimal. This region of the skull is of importance for Allosaurus taxonomy and phylogeny, particularly because Allosaurus has traditionally been reconstructed with an unusual cheek configuration, and because the European species Allosaurus europaeus has been said to be different from North American material in the configuration of these bones. Based on reexamination of articulated and disarticulated material from a number of repositories, we show that the jugal participates in the antorbital fenestra, contradicting the common interpretation. The jugal laterally overlies the lacrimal, and forms an extended antorbital fossa with this bone. Furthermore, we document previously unrecorded pneumatic features of the jugal of Allosaurus.

\section{Introduction}

The theropod dinosaur Allosaurus is certainly one of the best-known dinosaur taxa for scientists and the general public alike. It was first described on the basis of a fragmentary specimen from the Late Jurassic Morrison Formation by Marsh (1877). However, more complete material, including an almost complete skeleton from the same locality, Felch Quarry, as the type and several skulls from other Morrison localities were referred to the same taxon shortly after (Marsh, 1884; Osborn, 1903, 1912). The former specimen was described in detail in a monograph by Charles Gilmore in, 1920 (although under the name Antrodemus; see Madsen [1976] for discussion), through which it became a reference taxon for theropod anatomy in general.

A large assemblage of theropod bones was found in sediments of the Morrison Formation close to Cleveland, Utah, in, 1927, and excavation at the Cleveland-Lloyd dinosaur quarry in subsequent decades has yielded a vast amount of Late Jurassic dinosaur specimens (see Madsen, 
52 1976; Gates, 2005; Peterson et al., 2017). The most common dinosaur found at that site is

53 Allosaurus, which is represented by at least 46 individuals (Carpenter, 2010), although the

54 material is generally found disarticulated. The availability of such a large number of specimens

55 of a single taxon led Madsen (1976) to publish a revised osteology of Allosaurus, in which he

56 figured every individual bone for this genus, often in several views. It should be noted here that

Madsen (1976: 2) himself noted that his description and illustrations were not intended to give an

58

59

60

61

62

63

64

65

66

67

68

69

70

71

72

73

74

75

76

77

78

79

80

81

82 accurate account of the morphology of any individual element, but rather provide a composite reconstruction of the anatomy of this taxon. Nevertheless, due to his work, Allosaurus has become one of the best and most completely known theropod taxa, which is widely used in studies of theropod phylogeny, geometric morphometrics, biomechanics, and biology in general (e.g. Gauthier, 1986; Holtz, 1994; Rogers, 1998, 2005; Hanna, 2002; Rauhut, 2003; Rayfield et al., 2001; Rayfield, 2005; Carrano, Benson \& Sampson, 2012; Brusatte et al., 2012; Foth \& Rauhut, 2013a; Snively et al., 2013; Lautenschlager, 2015; Foth et al., 2015).

5 Due to the large number of specimens known for Allosaurus, several authors have observed variation among the material (Chure \& Madsen, 1996; Smith, 1998; Chure, 2000; Carpenter, 2010; Loewen, 2009), arriving at different conclusions regarding the taxonomy of the genus Allosaurus. Because the holotype material of the type species Allosaurus fragilis is not diagnostic, USNM 4734, the nearly complete specimen from Felch Quarry (Gilmore, 1920; Carrano, Loewen \& Evers, 2018), was proposed as a neotype (Paul \& Carpenter, 2010; supported by several comments, e.g. Carpenter \& Paul, 2015; Carrano, Loewen \& Evers, 2018). A second North American species, originally informally diagnosed in an unpublished $\mathrm{PhD}$ thesis (Chure, 2000) has recently been formally named as Allosaurus jimmadseni (Chure \& Loewen, in press). Further putative species, Allosaurus lucasi and Allosaurus amplus, are based on very fragmentary and probably undiagnostic material (Dalman, 2014; Galton, Carpenter \& Dalman, 2015). As the Morrison Formation was deposited over a duration of 7 million years and crops out over 1.2 million $\mathrm{km}^{2}$ (Maidment \& Muxworthy, 2019), reported variation among specimens of Allosaurus could possibly be explained by geographic or stratigraphic separation of occurrences. The taxonomy of Allosaurus needs to be revised, but this should only be done when the neotype for Allosaurus fragilis has been formalised by an ICZN decision, so it can be compared in detail with the species described by Chure \& Loewen (in press). Here, we use the taxon Allosaurus without species epithet due to the unsolved taxonomic issues. However, our observations are 
83 based on specimens that have been referred to both species, and we have not found any

84 differences between those for the elements of interest.

85

86

87

88

89

90

91

92

93

94

95

96

97

98

99

100

101

102

103

104

105

106

107

108

109

110

111

112 In order to assess the configuration of the anterior cheek region of Allosaurus, we studied

113 articulated skulls (DINO 11541; MOR 693; DINO 2560 [UUVP 6000]), a disarticulated skull

The cranial morphology of Allosaurus was first described by Osborn $(1903,1912)$ and Gilmore (1920). These descriptions were based on three almost complete, but partially disarticulated and/or distorted and damaged skulls, two from Bone Cabin Quarry (Osborn, 1903, 1912) and one from the type locality of the genus, Felch Quarry (Gilmore, 1920). All specimens were, unfortunately, damaged or incomplete in the anterior cheek region, and although both Osborn (1903: 697) and Gilmore (1920: 29) stated that the jugal formed part of the margin of the antorbital fenestra, this was not unambiguously clear from their illustrations, as parts of this region were reconstructed.

In contrast, Madsen (1976: pl. 1) reconstructed the skull of Allosaurus with an anteriorly tapering jugal that is excluded from the margin of the antorbital fenestra in lateral view. This reconstruction turned out to be very influential, with consequences for several kinds of studies including this taxon. Thus, in a multitude of phylogenetic studies that used differences in the expression of the jugal on the rim of the antorbital fenestra as a phylogenetic character, Allosaurus was coded as lacking such an expression (e.g. Holtz, 1994, 1998; Currie \& Carpenter, 2000; Rauhut, 2003; Holtz, Molnar \& Currie, 2004; Smith et al., 2007; Benson, Carrano \& Brusatte, 2010; Carrano, Benson \& Sampson, 2012). Besides, a study of the biomechanical significance of suture morphology of this taxon also used this configuration (Rayfield, 2005). Furthermore, the clear presence of an expression of the jugal on the rim of the antorbital fenestra was considered an important character to distinguish the European species of Allosaurus, A. europaeus, from its North American counterparts (Mateus, Walen \& Antunes, 2006; see also Malafaia et al., 2007).

Here, we review the evidence for the configuration of the maxilla, lacrimal and jugal and its significance for the question whether the latter bone participated in the rim of the antorbital fenestra in Allosaurus.

\section{Materials \& Methods}

Peer) reviewing PDF | (2019:11:42924:1:1:NEW 27 Dec 2019) 
114 (SMA 0005), and isolated elements of this taxon from the Morrison Formation of North

115 America. Isolated elements included numerous specimens of maxillae, jugals and lacrimals from

116 the Cleveland-Lloyd Dinosaur Quarry of Utah, from which several elements were selected, in

117 which the regions of interest are particularly well preserved. These specimens included three left

118 maxillae (UMNH VP 9168, 9208 and 9216), a left (UMNH VP 9475) and a right lacrimal

119 (UMNH VP 9473), and two right (UMNH VP 9083 and 9085) and one left jugal (UMNH VP

120 8972). Two further left jugals (UMNH VP 8973 and 8974) were documented, because in these

121 pneumatic features were well visible due to breakage.

122

123 Institutional abbreviations. AMNH, American Museum of Natural History, New York, USA;

124 DINO, Dinosaur National Monument, Jensen, Utah, USA; ML, Museu da Lourinhã, Lourinhã,

125 Portugal; MOR, Museum of the Rockies, Bozeman, Montana, USA; NCSM, North Carolina

126 Museum of Natural Sciences, Raleigh, North Carolina, USA; PVSJ, Paleontología de

127 Vertebrados, Universidd de San Juan, Argentina; SMA, Saurier-Museum Aathal, Switzerland;

128 UMNH, Utah Museum of Natural History, Salt Lake City, Utah; USNM, United States National

129 Museum of Natural History, Washington DC, USA.

130

\section{Results}

132

133 The configuration of the anterior cheek in Allosaurus: Madsen's interpretation

135 As noted above, Madsen (1976) described the osteology of Allosaurus on the basis of abundant,

136 but disarticulated material from the Cleveland-Lloyd dinosaur quarry of Utah, although he used a

137 partially articulated specimen from Dinosaur National Monument, DINO 2560 (formerly UUVP

138 6000), as guidance (Madsen, 1976: 2). In his skull reconstruction, Madsen (1976: pl. 1)

139 illustrated a broad contact between the ventral process of the lacrimal and the posterior process

140 of the maxilla, visible in lateral view. Both bones form the posteroventral margin of the internal

141 antorbital fenestra, while the jugal is excluded from the antorbital fenestra. In contrast to the

142 individual reconstruction of the jugal (Madsen, 1976: pl. 4D, E), the anterior process of the jugal

143 in the skull reconstruction was illustrated to be subdivided into a long and tapering anteroventral

144 and a shorter posterodorsal process, which together formed a deeply concave anterodorsal 
145 margin. In his figures of the individual elements, Madsen (1976) correctly illustrated the jugal

146 with a pronounced anterior expansion, but indicated that most of this expansion would have been

147 overlapped laterally by the lacrimal in the articulated skull (Madsen, 1976: pl. 4D), thus

148 interpreting the depressed area on the anterior expansion as the facet for the latter bone. His

149 interpretation was probably influenced by the curved rim of the antorbital fossa on the jugal,

150 which stands out prominently in articulated skulls, and was interpreted as the jugal-lacrimal

151 suture, and the very thin bone anterior to it, which resembles the distal end of the ventral process

152 of the lacrimal.

153

154 Configuration of the anterior cheek in other theropods

155

156 The morphology of the cheek region of theropod dinosaurs has recently been reviewed by

157 Sullivan \& Xu (2017) and Wang et al. (2017), focusing primarily on the morphology of the

158 jugal. Apart from a few exceptions, the anterior process of the jugal in theropods participates in

159 the posteroventral margin of the antorbital fenestra. In small-bodied theropods this process is

160 usually slender and tapering, but it is dorsoventrally expanded in many large-bodied taxa.

161 In contrast, the exclusion of the jugal from the antorbital fenestra is occasionally present

162 in theropods, including various coelophysids (Raath, 1977; Colbert, 1989; Rowe, 1989; Tykoski,

163 1998; Bristowe \& Raath, 2005), the ceratosaurid Ceratosaurus (Gilmore, 1920; Madsen \&

164 Welles, 2000), and the basal alvarezsaurid Haplocheirus (Choiniere et al., 2014), while it is the

165 common morphology in non-avian Pygostylia (Wang et al., 2017). In addition, the configuration

166 was described for the basal theropod Zupaysaurus (Ezcurra, 2007) and the megalosaurid

167 Torvosaurus (Brusatte et al., 2010). However, further preparation of the anterior cheek region of

168 Zupaysaurus revealed a jugal contribution to the antorbital fenestra (Martín Ezcurra, pers.

169 comm., 2012), while the incomplete preservation of the maxilla and jugal in Torvosaurus does

170 not allow a proper judgement of the true morphology. However, all taxa for which the exclusion

171 of the jugal from the antorbital fenestra can be confirmed with no doubt show a laterally exposed

172 contact between maxilla and lacrimal, the extent of which depends primarily on the shape of the

173 lacrimal ventral process. Accordingly, the contact is very broad in Coelophysis and

174 Ceratosaurus.

Peer) reviewing PDF | (2019:11:42924:1:1:NEW 27 Dec 2019) 
175 Regardless of the jugal contribution to the margin of the antorbital fenestra, the relative 176 arrangement and articular surfaces of bones involved in the formation of the cheek are the same 177 in all non-avian theropods: the jugal overlaps the lateral surface of the ventral process of the 178 lacrimal. As noted by Sereno \& Novas (1993), this is a saurischian synapomorphy.

179 Consequentially, the ventral end of the lacrimal is positioned medially to the jugal, so that a 180 lacrimal-maxilla contact is not externally visible in taxa in which the jugal extends to the 181 antorbital fenestra. However, even in taxa with this configuration, there is an internal contact 182 between the lacrimal and the maxilla. The usually anteroposteriorly expanded basal plate of the 183 lacrimal sits in a facet on the dorsal shelf of the maxilla that is situated medially to the groove for 184 the jugal. This is the case even in taxa in which the lacrimal seems to be dorsoventrally short and 185 is widely separated from the maxilla in external view of the articulated skull, such as in Herrerasaurus (PVSJ 53).

Data from specimens of Allosaurus

The posterior end of the maxilla of Allosaurus shows facets for the articulation with the jugal,

191 lacrimal and palatine, which are roughly mediolaterally aligned. The contact with the jugal is 192 positioned laterally with regard to the contact with the lacrimal, and both these contact facets 193 form grooves on the dorsal surface of the posterior processes of the maxilla (Fig. 1). The facet

194 for the palatine is the medialmost of the three contacts, and is visible on the medial surface of the 195 maxilla.

196 The jugal facet is developed as a narrow, dorsally facing groove (Fig. 1C-D), which 197 extends from the posteroventral corner of the bone to the level of the third alveolous as counted 198 from posterior. The posteriormost part of this groove is exposed laterally, but a dorsally 199 ascending lamina conceals the anterior part of the groove in lateral view (Fig. 1C-D). The 200 lacrimal facet is subparallel to the jugal facet, but separated from the former by a low, but 201 relatively broad ridge (Fig. 1C-D). The lacrimal facet itself is developed as a subtle groove, 202 which extends along the medial margin of the dorsal surface of the posterior process of the 203 maxilla. This facet continues marginally further anteriorly than the facet for the jugal, forming a 204 broad contact between maxilla and lacrimal. The third articulation facet, the palatine facet of the 205 maxilla, is much broader than the other facets described above. It is positioned medial to the 
206 lacrimal contact, and is developed as a roughened longitudinal area that spans from the first to 207 approximately the seventh tooth position as counted from posterior. The dorsal margin of the 208 palatine facet is developed as a near vertical shelf of bone, which prohibits a contact between the 209 palatine and lacrimal.

210 The lacrimal has a mediolaterally thin, and anteroposteriorly expanded ventral process 211 that articulates with the maxilla and jugal (Fig. 2). The ventral process can be divided into two 212 units. Anteriorly and ventrally, the ventral process forms a thin blade of bone (medial lamina), 213 which is recessed from a thickened posterior margin (lateral lamina) (Fig. 2B-C). A vertically 214 directed, anteriorly facing groove invades the thick posterior margin at the posterior end of the 215 thin blade (Fig. 2B). We interpret this incision as a facet for the posterior margin of the anterior

216 blade of the jugal. Consequently, the anterior process of the jugal covers large parts of the

217 lacrimal blade laterally when both bones are articulated. In his reconstruction of the lacrimal, 218 Madsen (1976: pl. 5A) illustrated a deep notch in the ventral margin of lacrimal. However, as 219 this region is often broken in Allosaurus specimens (see Osborn, 1903; Carpenter, 2010), the 220 presence of such a notch is probably an artefact. In those specimens (e.g., SMA 0005) in which 221 the ventral end of the ventral process is fully intact, this margin is almost straight (Fig. 2). This 222 observation fits with the dorsally exposed lacrimal facet groove of the maxilla.

223 The jugal of Allosaurus has a dorsally expanded anterior process that contacts the maxilla 224 and lacrimal. This process is often incompletely preserved (even in articulated specimens), but it 225 is nearly completely preserved in the specimen SMA 0005 (Fig. 3). The jugal of Allosaurus is 226 relatively tightly articulated with the maxilla via a ventral and a medial contact. The ventral 227 contact is formed by the relatively thin, keel-like margin of the jugal, which slots into the 228 dorsally exposed jugal facet on the posterior process of the maxilla. The second facet is a wedge229 shaped, posteriorly tapering depression in the lateral surface of the jugal, which receives the 230 lateral part of the posterior process of the maxilla (Fig. 3).

231 The lateral surface of the anterior process of the jugal is characterised by a sharp, 232 concavely curved step-like ridge, which separates the process into an extremely thin, blade-like 233 anterodorsal region, which is recessed from a thicker posteroventral region (Fig 3). We identify 234 this ridge as the posteroventral margin of the antorbital fossa. This margin is slightly excavated 235 to a shallow groove posteroventrally, as evident from several better-preserved specimens, such as 236 UMNH VP 9085, UMNH VP 8972 and SMA 0005. Unlike reported in other works (e.g., 
237 Brusatte et al., 2010; Eddy \& Clarke, 2011), there is a small pneumatic foramen located within

238 the margin of this groove (see Currie \& Zhao, 1993; Coria \& Currie, 2006). The foramen

239 excavates posteriorly into the anterior process of the jugal (Fig. 4). Evidence for the pneumatic

240 invasion of the jugal via the anterior process is also given by several specimens in which the

241 anterior process of the jugal is broken off, exposing a pneumatic recess within it (e.g. UMNH VP

242 8973, UMNH VP 8974; Fig. 4). Because the anterior blade is extremely thin, it is often

243 incompletely preserved (see Chure, 2000; Loewen, 2009; Carpenter, 2010), leading to different

244 interpretations regarding the anterodorsal morphology of the process, specifically with regard to

245 its extend into the antorbital fenestra (e.g. Madsen, 1976 vs. this study). However, some

246 specimens (e.g., SMA 0005) show that the anterodorsal margin is convexly rounded, as

247 reconstructed by Madsen for the isolated jugal (1976: pl. 4D, E). The thickened posterior margin

248 of the anterior jugal process faces toward the orbit and slots into the facet in the lateral lamina of

249 the lacrimal (see above). Consequentially, the lacrimal wraps around the posterior edge of the

250 jugal, which is particularly well visible in articulated specimens (Fig. 5). The same articulation is

251 also present in Acrocanthosaurus (NCSM 14345, pers. obs. by all authors, 2012). This contact

252 appears to be relatively tight, so that kinematic movements between the lacrimal and jugal seem

253 unlikely.

254 The thin jugal blade lies on the lateral surface of the medial lamina of the lacrimal. The

255 low ridge that marks the margin of the antorbital fossa on the jugal aligns with the edge of the

256 posteriorly thickened margin of the lacrimal, so that the antorbital fossa is continuous between

257 both bones. This morphology can be also observed in various articulated Allosaurus skulls,

258 including MOR 693 (pers. obs. SWE, 2014), UUVP 6000 (pers. obs. SWE and OWMR, 2016),

259 and DINO 11541 (pers. obs. SWE and OWMR, 2016) (Fig. 3).

260

261

\section{Discussion}

262

263 The re-examination of the bones of the anterior cheek region in Allosaurus demonstrates that the

264 famous skull reconstruction by Madsen (1976) is erroneous with respect to morphology of the

265 anterior process of the jugal and its articulation with the lacrimal and maxilla. The anterior

266 process of the jugal in Allosaurus is in fact enlarged and plate-like (Fig. 3) and covers the lateral

267 side of the lacrimal in its ventral part (Figs 5-6). The anterodorsal margin of the anterior process 
268 of the jugal extends into the internal antorbital fenestra. This morphology was previously

269 described by Osborn (1903) for the disarticulated specimens AMNH 600, and by Gilmore (1920)

270 for the artificially articulated USNM 4734. In addition, other skull reconstructions based on

271 UUVP 6000 were illustrated with this configuration too (see Bakker, 1998: fig. 3B; Paul, 2002:

272 fig. 10.2F; Fastovsky \& Weishampel, 2005: fig. 12.2F), but without commenting on the

273 discrepancy to Madsen's (1976) reconstruction of the same specimen. As Madsen (1976: pl. 4D,

274 E) figures the morphology of the anterior process of the jugal correctly in the individual bone

275 reconstructions, we can only speculate why his reconstruction of the skull is erroneous. Based on

276 its position, the concavely shaped and gently recessed anterodorsally surface of the anterior

277 process (Madsen, 1976: pl. 1) clearly represents the jugal part of the antorbital fossa, which is

278 continuous with the respective margins of the ventral process of the lacrimal and posterior

279 process of the maxilla.

280 However, our current observations confirm a broad contact between maxilla and lacrimal

281 in Allosaurus as illustrated in Madsen (1976: pl. 1), but the articulation is covered laterally by the

282 anterior process of the jugal and only visible from medial view. A similar morphology can be

283 found in the carcharodontosaurid Acrocanthosaurus (right side of NCSM 14345, pers. obs. by all

284 authors, 2012). In addition, Hendrickx \& Mateus (2014) described a prominent medially located

285 articulation facet for the lacrimal on the dorsal side of the distal end of the posterior process of

286 the maxilla of Torvosaurus gurneyi. This contact is also present in ornithomimosaurs (Kobayashi

287 et al., 2003), therizinosaurids (Clark, Perle \& Norrell, 1994; Lautenschlager, 2014),

288 oviraptorosaurs (Clark, Norell \& Rowe, 2002; Balanoff et al., 2009, 2012) and non-avian

289 Pygostylia (Wang et al., 2017), while it is absent in abelisaurids (Bonaparte, Novas \& Coria,

290 1990; Sampson \& Witmer, 2007; Canale et al., 2009), tyrannosaurids (Currie, 2003),

291 dromaeosaurids (Turner, Makovicky \& Norell, 2012), troodontids (Tsuihiji et al., 2014) and

292 crown-group birds (Zusi, 1993).

293 Furthermore, the new observations have implications for the diagnosis of the European

294 Allosaurus europaeus (Mateus, Walen \& Antunes, 2006; Fig. 5D) as a distinct species, for which

295 the jugal participation in the antorbital fenestra was listed as one of the few autapomorphic

296 characters that differentiate it from the North American species. Besides, the authors listed the

297 absence of a lacrimal-maxilla contact as a further apomorphy, which is related to the former

298 character. However, as pointed out above, this is only true for the lateral view, while a medial 
299 contact between both bones was almost certainly present. Unfortunately, this cannot be verified

300 at the moment as the internal side of the skull is filled with matrix, but the consistent nature of

301 this contact in regard to Allosaurus specimens examined for this study allow inferring the

302 presence of this contact with high confidence. All other diagnostic features of Allosaurus

303 europaeus have been questioned to be truly unique, and some have proven to be variably present

304 in North American Allosaurus specimens (Mafalaia et al., 2007) Therefore, a re-evaluation of the

305 European species is necessary, as currently none of the originally proposed diagnostic features

306 are uniquely present in the holotype of Allosaurus europeaus.

307

308 Conclusions

309

310 The cheek region of Allosaurus conforms to the general pattern observed in basal tetanurans: the

311 jugal overlies the lateral surface of the lacrimal, and both bones articulate with the maxilla. The

312 anterior process of the jugal of Allosaurus is anterodorsally expanded and contributes to the

313 antorbital fenestra and forms parts of the antorbital fossa, contradicting the famous

314 reconstruction by Madsen (1976). The articulation facets between the maxilla, lacrimal and jugal

315 are relatively complex and indicate that the contacts between these cheek bones were relatively

316 strong, probably allowing little if any movement. The configuration of cheek bones does not vary

317 between the examined specimens in Allosaurus, and our observations furthermore indicate that

318 the European species Allosaurus europaeus did not differ in this regard from North American

319 material.

320

321

Acknowledgements

322

323 The authors would like to thank several people who provided access to specimens under their

324 care. These are, in no particular order, Carrie Levitt-Bussian and Randall Irmis (UMNH), Brooks

325 Britt and Rodney Scheets (BYU), Dan Chure (DINO/DNM), Octavio Mateus and Simão Mateus

326 (ML), Vince Schneider and Lindsay Zanno (NCSM), Jack Horner, John Scanella and Bob

327 Harmon (MOR), Kirby Siber, Thomas Bollinger and Ben Pabst (SMA), Mark Norell and Carl

328 Mehling (AMNH), Paul Barrett (NHMUK). We would also like to thank Roger Benson for 
329 providing additional photographs of Neovenator salerii. We are thankful to Mark Loewen, Matt

330 Carrano, Dan Chure, and Octavio Mateus for numerous discussions about Allosaurus.

331

332

333

334

Bakker RT. 1998. Brontosaur killers: Late Jurassic allosaurids as sabre-tooth cat analogues. Gaia

335 15:145-158.

336

337

Balanoff AM, Norell MA. 2012. Osteology of Khaan mckennai (Oviraptorosauria: Theropoda).

338

Bulletin of the American Museum of Natural History 372:1-77.

339

340

Balanoff AM, Xu X, Kobayashi Y, Matsufune Y, Norell MA. 2009. Cranial osteology of the

341 theropod dinosaur Incisivosaurus gauthieri (Theropoda: Oviraptorosauria). American Museum

342

343

344

Novitates 3651:1-35.

345

Benson RBJ, Carrano MT, Brusatte SL. 2010. A new clade of archaic large-bodied predatory

346

dinosaurs (Theropoda: Allosauroidea) that survived to the latest Mesozoic. Naturwissenschaften 97:71-78.

347

348

Bonaparte JF, Novas FE, Coria RA. 1990. Carnotaurus sastrei Bonaparte, the horned, lightly

349 built carnosaur from the Middle Cretaceous of Patagonia. Contributions in Science 416:1-42. 350

351

352

353

354

355

Bristowe A, Raath MA. 2004. A juvenile coelophysoid skull from the Early Jurassic of Zimbabwe, and the synonymy of Coelophysis and Syntarsus. Palaeontologia Africana 40:31-41.

356

Brusatte SL, Benson RBJ, Currie PJ, Zhao X. 2010. The skull of Monolophosaurus jiangi

(Dinosauria: Theropoda) and its implications for early theropod phylogeny and evolution.

357

358

Zoological Journal of the Linnean Society 158:573-607.

359

Brusatte SL, Montanari S, Sakamoto M, Harcourt-Smith WEH. 2012. The evolution of cranial form and function in theropod dinosaurs: insight from geometric morphometrics. Journal of

360

361

362 Evolutionary Biology 25:365-377.

363

Canale IC, Scanferla CA, Agnolín FL, Novas FE. 2009. New carnivorous dinosaur from the late 364 Cretaceous of NW Patagonia and the evolution of abelisaurid theropods. Naturwissenschaften

365

366 96:409-414.

367

Carpenter K. 2010. Variation in a population of Theropoda (Dinosauria): Allosaurus from the 368 Cleveland-Lloyd Quarry (Upper Jurassic), Utah, USA. Paleontological Research 14:250-259. 
369 Carpenter K, Paul GS. 2015. Comment (Case 3506) on Allosaurus Marsh, 1877 (Dinosauria, 370 Theropoda): proposed conservation of usage by designation of a neotype for its type species

371 Allosaurus fragilis Marsh, 1877. The Bulletin of Zoological Nomenclature 72(1):79-80.

372

373 Carrano MT, Benson RBJ, Sampson SD. 2012. The phylogeny of Tetanurae (Dinosauria:

374 Theropoda). Journal of Systematic Palaeontology 10:211-300.

375

376 Carrano MT, Loewen MA, Evers SW. 2018. Comment (Case 3506) - Conservation of Allosaurus

377 Marsh, 1877 (Dinosauria, Theropoda): additional data in support of the proposed neotype for its

378 type species Allosaurus fragilis Marsh, 1877. The Bulletin of Zoological Nomenclature 75:59-

37964.

380

381 Choiniere JN, Clark JM, Norell MA, Xu X. 2014. Cranial osteology of Haplocheirus sollers

382 Choiniere et al., 2010 (Theropoda: Alvarezsauroidea). American Museum Novitates 3816:1-44.

383

384

Chure DJ. 2000. A new species of Allosaurus from the Morrison Formation of Dinosaur National

385

Monument (UT-CO) and a revision of the theropod family Allosauridae. Columbia University.

386

387

Chure DJ, Loewen MA. In press. Cranial anatomy of Allosaurus jimmadseni, a new species from

388

the lower part of the Morrison Formation (Upper Jurassic) of Western North America. PeerJ

389

390

Chure DJ, Madsen JHJ. 1996. Variation in aspects of the tympanic pneumatic system in a

391

population of Allosaurus fragilis from the Morrison Formation (Upper Jurassic). Journal of

392

Vertebrate Paleontology 16:63-66.

393

394

Clark JM, Norell MA, Rowe TB. 2002. Cranial anatomy of Citipati osmolskae (Theropoda,

395

Oviraptorosauria), and a reinterpretation of the holotype of Oviraptor philoceratops. American

396

Museum Novitates 3364:1-24.

397

398

Clark JM, Perle A, Norell MA. 1994. The Skull of Erlicosaurus andrewsi, a Late Cretaceus

399

"Segnosaur" (Theropoda: Therizinosauridae) from Mongolia. American Museum Novitates

400 3315:1-39.

401

402

Colbert EH. 1989. The Triassic dinosaur Coelophysis. Museum of Northern Arizona Bulletin

403 57:1-160.

404

405

Coria RA, Currie PJ. 2006. A new carcharodontosaurid (Dinosauria, Theropoda) from the Upper

406 Cretaceous of Argentina. Geodiversitas 28:71-118.

407 
408 Currie PJ. 2003. Cranial anatomy of tyrannosaurid dinosaurs from the Late Cretaceous of 409 Alberta, Canada. Acta Palaeontologica Polonica 48:191-226.

410

411 Currie PJ, Carpenter K. 2000. A new specimen of Acrocanthosaurus atokensis (Theropoda, 412 Dinosauria) from the Lower Cretaceous Antlers Formation (Lower Cretaceous, Aptian) of 413 Oklahoma, USA. Geodiversitas 22:207-246.

414

415 Currie PJ, Zhao X. 1993. A new carnosaur (Dinosauria, Theropoda) from the Jurassic of 416 Xinjiang, People's Republic of China. Canadian Journal of Earth Sciences 30:2037-2081.

417

418 Dalman SG. 2014. Osteology of a large allosauroid theropod from the Upper Jurassic (Tithonian)

419 Morrison Formation of Colorado, USA. Volumina Jurassica 12:159-180.

420

421

Eddy DR, Clarke JA. 2011. New information on the cranial anatomy of Acrocanthosaurus

422 atokensis and its implications for the phylogeny of Allosauroidea (Dinosauria: Theropoda). PLoS

423

424

425

426

427

428

429 ONE 6:e17932.

Ezcurra MD. 2007. The cranial anatomy of the coelophysoid theropod Zupaysaurus rougieri from the Upper Triassic of Argentina. Historical Biology 19:185-202.

Fastovsky DE, Weishampel DB. 2005. The evolution and extinction of the dinosaurs. Cambridge: Cambridge University Press.

430

431

432

Foth C, Evers SW, Pabst B, Mateus O, Flisch A, Patthey M, Rauhut OWM. 2015. New insights into the lifestyle of Allosaurus (Dinosauria: Theropoda) based on another specimen with multiple 433 pathologies. PeerJ 3:e940. DOI: 10.7717/peerj.940.

434

435

Foth C, Rauhut OWM. 2013. Macroevolutionary and morphofunctional patterns in theropod

436 skulls: a morphometric approach. Acta Palaeontologica Polonica 58:1-16.

437

Galton PM, Carpenter K, Dalman SG. 2015. The holotype pes of the Morrison dinosaur Camptonotus amplus Marsh, 1879 (Upper Jurassic, western USA) - is it Camptosaurus, Sauropoda or Allosaurus? Neues Jahrbuch für Geologie und Paläontologie, Abhandlungen $441 \quad 275: 317-335$.

442

Gates TA. 2005. The Late Jurassic Cleveland-Lloyd Dinosaur Quarry as a drought-induced 444 assemblage. Palaios 20:363-375.

445

446 Gauthier JA. 1986. Saurischian monophyly and the origin of birds. Memoirs of the California 447 Academy of Science 8:1-55. 
449 Gilmore GW. 1920. Osteology of the carnivorous dinosauria in the United States National

450 Museum, with special reference to the genera Antrodemus (Allosaurus) and Ceratosaurus.

451 Bulletin of the United States National Museum 110:1-159.

452

453 Hanna RR. 2002. Multiple injury and infection in a sub adult theropod dinosaur Allosaurus

454 fragilis with comparisons to allosaur pathology in the Cleveland-Lloyd Dinosaur Quarry

455 Collection. Journal of Vertebrate Paleontology 22:76-90.

456

457 Hendrickx C, Mateus O. 2014. Torvosaurus gurneyi n. sp., the largest terrestrial predator from

458 Europe, and a proposed terminology of the maxilla anatomy in nonavian theropods. PLoS ONE

459 9:e88905. DOI: 10.1371/journal.pone.0088905.

460

461 Holtz TRJ. 1994. The phylogenetic position of the Tyrannosauridae: implications for theropod 462 systematics. Journal of Paleontology 68:1100-1117.

463

464

465

466

467

468

469

470

471

472

473

474

475

476

Holtz TRJ. 1998. A new phylogeny of the carnivorous dinosaurs. Gaia 15:5-61.

Holtz TRJ, Molnar RE, Currie PJ. 2004. Basal Tetanurae. In: Weishampel DB, Dodson P, Osmólska H eds. The Dinosauria. Berkeley: University of California Press, 71-110.

Kobayashi Y, Lü J. 2003. A new ornithomimid dinosaur with gregarious habits from the Late Cretaceous of China. Acta Palaeontologica Polonica 48:235-259.

Lautenschlager S. 2015. Estimating cranial musculoskeletal constraints in theropod dinosaurs. Royal Society Open Science 2:150495.

477

Lautenschlager S, Witmer LM, Perle A, Zanno LE, Rayfield EJ. 2014. Cranial anatomy of

Erlikosaurus andrewsi (Dinosauria, Therizinosauria): new insights based on digital

478

479 reconstruction. Journal of Vertebrate Paleontology 34:1263-1291.

480

Loewen MA. 2009. Variation in the Late Jurassic theropod dinosaur Allosaurus: ontogenetic, functional, and taxonomic implications. University of Utah, Salt Lake City.

481

482

Madsen JHJ. 1976. Allosaurus fragilis: a revised osteology. Utah Geological and Mineralogical 483 Survey Bulletin 109:3-163.

484

485

Madsen JHJ, Welles SP. 2000. Ceratosaurus (Dinosauria, Theropoda), a revised osteology. Utah 486 Geology Survey Miscellaneous Publication 00-2:1-80.

487 
488 Maidment SCR, Muxworthy A. 2019. A chronostratigraphic framework for the Upper Jurassic

489 Morrision Formation, western U.S.A. Journal of Sedimentary Research 89:1017-1038.

490

491 Malafaia E, Ortega F, Escaso F, Silva B, Ramalheiro G, Dantas P, Moniz C, Barriga F. 2007. A

492 preliminary account of a new Allosaurus individual fromthe Lourinhã Group (Upper Jurassic of

493 Torres Vedras, Portugal). In: Abstracts book of the IV International Symposium about Dinosaurs

494 Palaeontology and their Environment, Salas de los Infantes. 243-251.

495

496 Marsh OC. 1877. Notice of new dinosaurian reptiles from the Jurassic formation. American

497 Journal of Science and Arts 14:514-516.

498

499 Marsh OC. 1884. Principal characters of American Jurassic dinosaurs. Part 8. The order

500 Theropoda. American Journal of Science 27:329-341.

501

502 Mateus O, Walen A, Antunes MT. 2006. The large theropod fauna of the Lourinhã Formation

503 (Portugal) and its similarity to the Morrison Formation, with a description of a new species of

504 Allosaurus. New Mexico Museum of Natural History and Science, Bulletin 36:1-7.

505

506 Osborn HF. 1903. The skull of Creosaurus. Bulletin of the American Museum of Natural History 507 19:697-701.

508

509 Osborn HF. 1912. Crania of Tyrannosaurus and Allosaurus. Memoirs of the American Museum

510 of Natural History 1:1-30.

511

512 Paul GS. 2002. Dinosaurs of the air: the evolution and loss of flight in dinosaurs and birds.

513 Baltimore: The John Hopkins University Press.

514

515 Paul GS, Carpenter K. 2010. Case 3506 - Allosaurus Marsh, 1877 (Dinosauria, Theropoda):

516 proposed conservation of usage by designation of a neotype for its type species Allosaurus

517 fragilis Marsh, 1877. Bulletin of Zoological Nomenclature 67:53-56.

518

519 Peterson JE, Warnock JP, Eberhart SL, Clawson SR, Noto CR. 2017. New data towards the

520 development of a comprehensive taphonomic framework for the Late Jurassic Cleveland-Lloyd

521 Dinosaur Quarry, Central Utah. PeerJ 5:e3368. DOI: 10.7717/peerj.3368.

522

523

Raath MA. 1977. The anatomy of the Triassic theropod Syntarsus rhodesiensis (Saurischia:

524

Podokesauridae) and a consideration of its biology. Rhodes University, Salisbury.

525

526 Rauhut OWM. 2003. The interrelationships and evolution of basal theropod dinosaurs. Special

527 Papers in Palaeontology 69:1-213. 
528

529

530

531

532

533

534

535

536

537

538

539

540

541

542

543

544

545

546

547

548

549

550

551

552

553

554

555

556

557

558

559

560

561

562

563

564

565

566

567
Rayfield EJ. 2005. Using Finite-Elemente Analysis to investigate suture morphology: a case study using large carnivorous dinosaurs. The Anatomical Record 283A:349-365.

Rayfield EJ, Norman DB, Horner CC, Horner JR, Smith PM, Thomason JJ, Upchurch P. 2001. Cranial design and function in a large theropod dinosaur. Nature 409:1033-1037.

Rogers SW. 1998. Exploring dinosaur neuropaleobiology: viewpoint computed tomography scanning and analysis of an Allosaurus fragilis endocast. Neuron 21:673-679.

Rogers SW. 2005. Reconstructing the behaviors of extinct species: an excursion into comparative paleoneurology. American Journal of Medical Genetics 13A:349-356.

Rowe TB. 1989. A new species of the theropod dinosaur Syntarsus from the Early Jurassic Kayenta Formation of Arizona. Journal of Vertebrate Paleontology 9:125-136.

Sampson SD, Witmer LM. 2007. Craniofacial anatomy of Majungasaurus crenatissimus (Theropoda: Abelisauridae) from the Late Cretaceous of Madagascar. Society of Vertebrate Paleontology Memoir 8:32-102.

Sereno PC, Novas FE. 1993. The skull and neck of the basal theropod Herrerasaurus ischigualastensis. Journal of Vertebrate Paleontology 13:451-476.

Smith DK. 1998. A morphometric analysis of Allosaurus. Journal of Vertebrate Paleontology 18:126-142.

Smith ND, Makovicky PJ, Hammer WR, Currie PJ. 2007. Osteology of Cryolophosaurus ellioti (Dinosauria: Theropoda) from the Early Jurassic of Antarctica and implications for early theropod evolution. Zoological Journal of the Linnean Society 151:377-421.

Snively E, Cotton JR, Ridgely RC, Witmer LM. 2013. Multibody dynamics model of head and neck function in Allosaurus (Dinosauria, Theropoda). Palaeontologia Electronica 16:11A.

Sullivan C, Xu X. 2017. Morphological diversity and evolution of the jugal in dinosaurs. The Anatomical Record 300:30-48.

Tsuihiji T, Barsbold R, Watabe M, Tsogtbaatar K, Chinzorig T, Fujiyama Y, Suzuki S. 2014. An exquisitely preserved troodontid theropod with new information on the palatal structure from the Upper Cretaceous of Mongolia. Naturwissenschaften 101:131-142.

Peer] reviewing PDF | (2019:11:42924:1:1:NEW 27 Dec 2019) 
568 Turner AH, Makovicky PJ, Norell MA. 2012. A review of dromaeosaurid systematics and

569 paravian phylogeny. Bulletin of the American Museum of Natural History 371:1-206.

570

571 Tykoski RS. 1998. The osteology of Syntarsus kayentakatae and its implications for ceratosaurid 572 phylogeny. Austin: The University of Texas, Austin.

573

574 Wang M, Hu H. 2017. A comparative morphological study of the jugal and quadratojugal in 575 early birds and their dinosaurian relatives. The Anatomical Record 300:62-75.

576

577 Zusi RL. 1993. Patterns of diversity in the avian skull. In: Hanken J, Hall BK eds. The skull. Vol. 578 2. Patterns of structural and systematic diversity. Chicago: University of Chicago Press, 391579437.

580

581

582

583

584 


\section{Figure 1}

Completely preserved right lacrimal of SMA 0005, Allosaurus jimmadsoni.

(A) lateral view. (B) close-up of ventral process in lateral view. (C) line-drawing of $B$. Arrows in B indicate groove for articulation of jugal. Abbreviations: j c, jugal contact; llam, lateral lamina; mlam, medial lamina; mx c, maxilla contact. Scale bar in A equals $10 \mathrm{~cm}$; scale bar in $B-C$ equal $3 \mathrm{~cm}$.

A

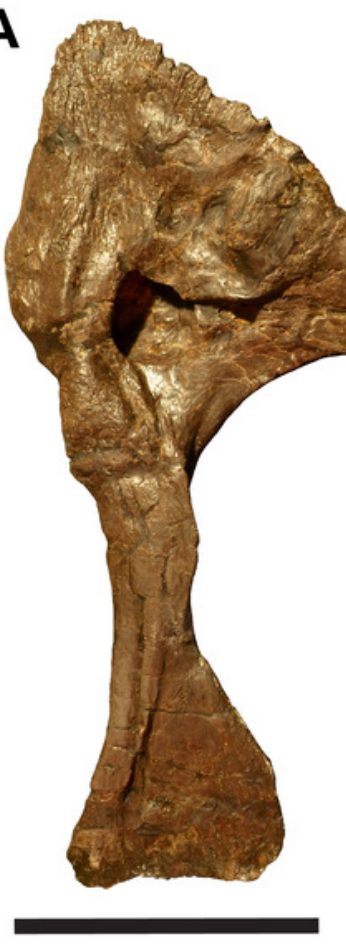

B

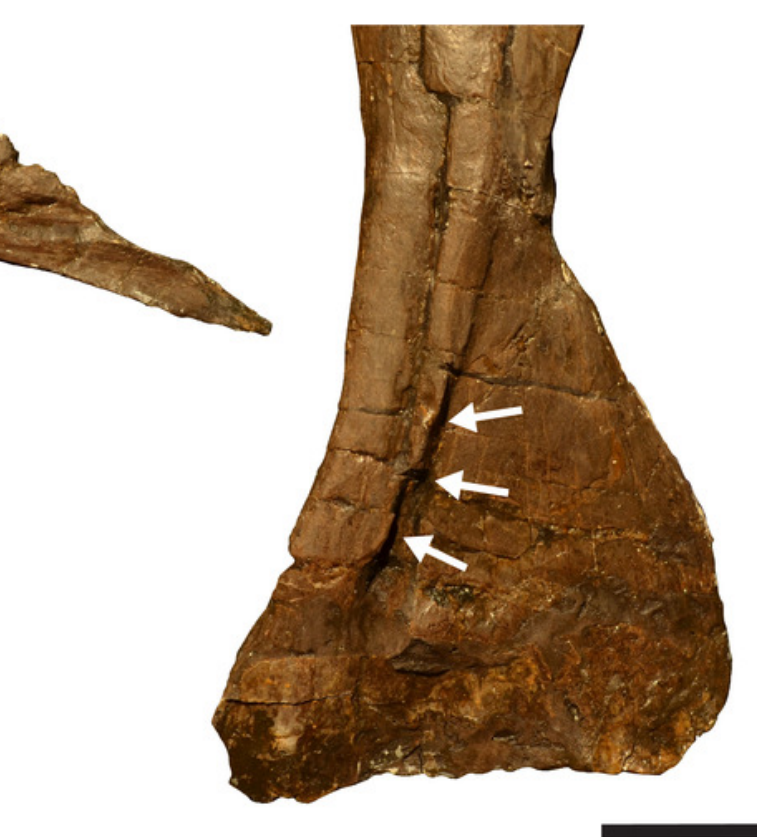

C

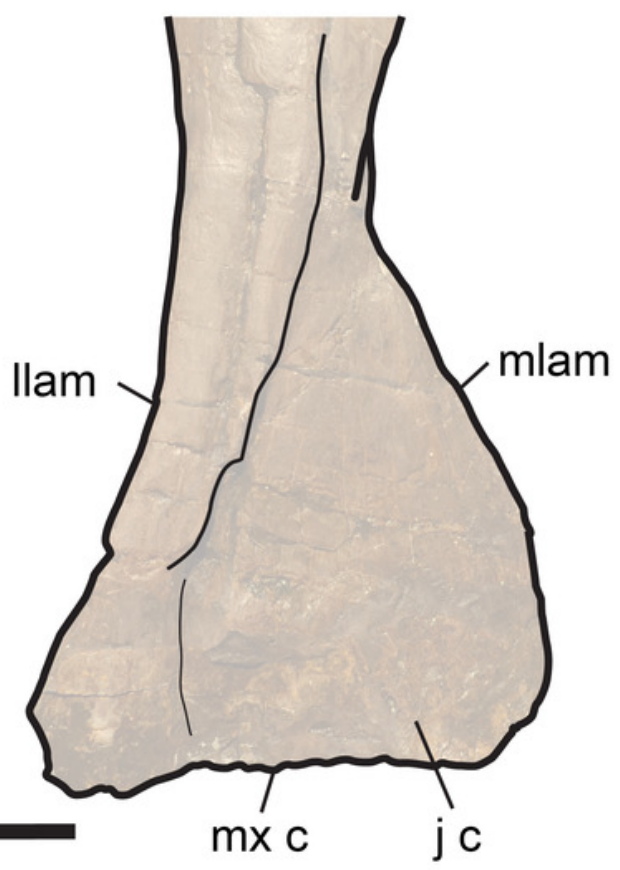




\section{Figure 2}

Incompletely preserved left maxilla of UMNH VP 9216, Allosaurus fragilis, showing details of the posterior process.

(A) lateral view. (B) dorsal view. (C) close-up of posterior process in dorsal view. (D) linedrawing of C. Dashed box in B shows region shown in more detail in C-D. Abbreviations: dasl, dorsally ascending lamina; dasm, dorsally ascending margin of posterior process; djf, dorsal jugal facet of maxilla; laf, lacrimal facet.Scale bar in A-B equals $10 \mathrm{~cm}$; scale bar in C-D equals $3 \mathrm{~cm}$. 

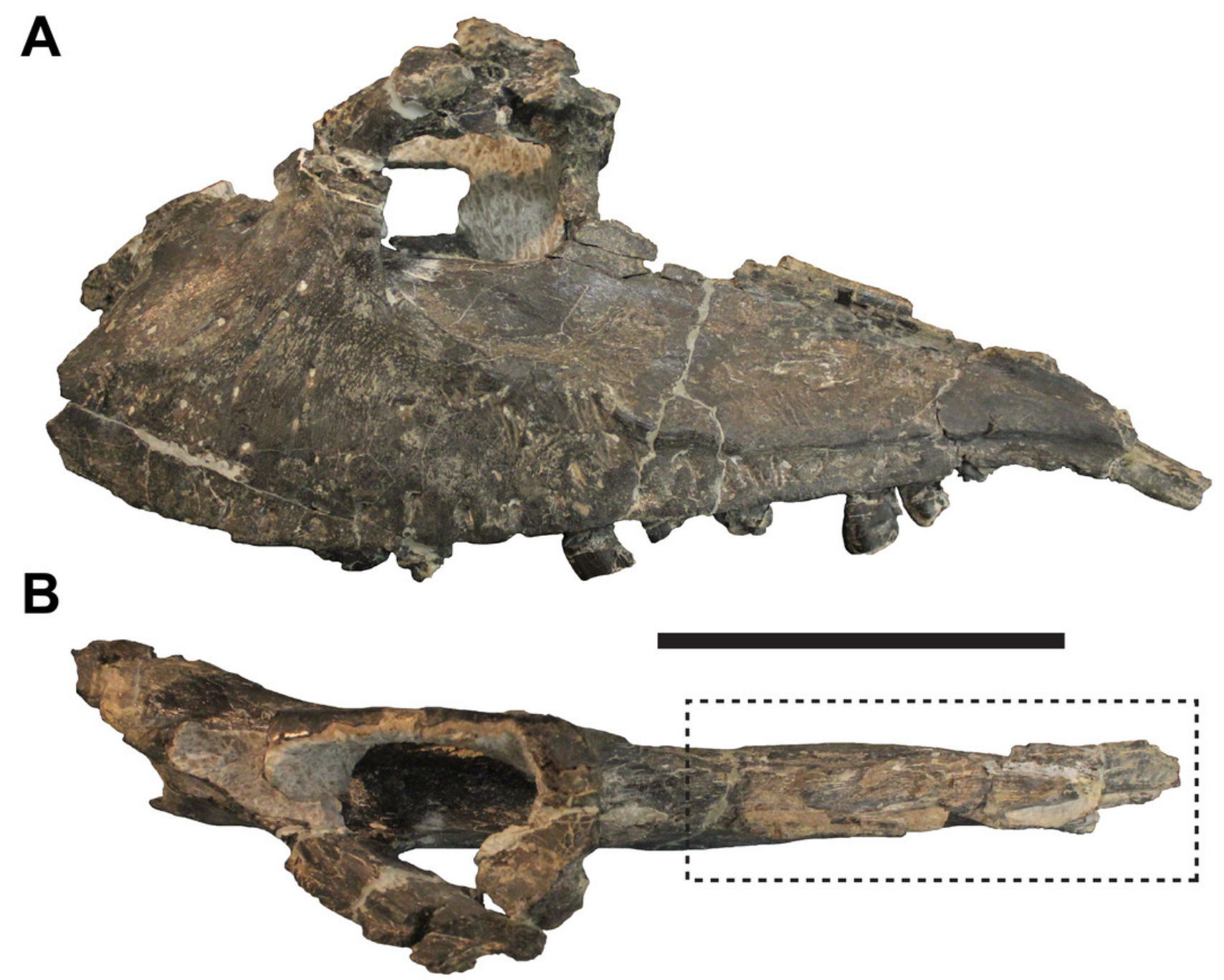

C
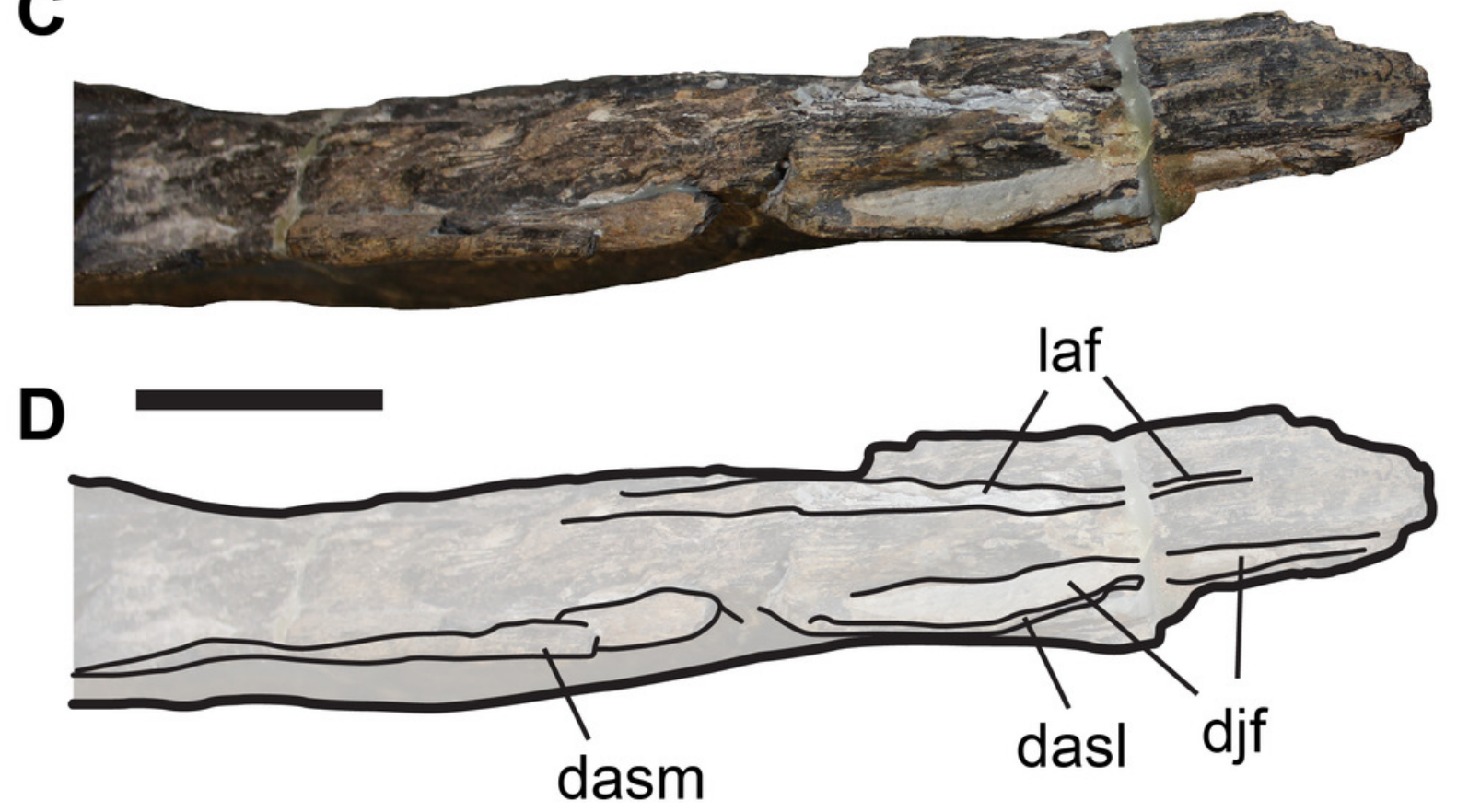

Peer] reviewing PDF | (2019:11:42924:1:1:NEW 27 Dec 2019) 


\section{Figure 3}

Completely preserved left jugal of SMA 0005, Allosaurus jimmadsoni.

(A) lateral view. (B) line drawing of $A$. (C) close-up of anterior jugal process in lateral view. (D) line-drawing of B. (E) medial view. (F) line-drawing of E. Abbreviations: aof, antorbital fossa; dep, depression; ect c, ectopterygoid contact; la c lacrimal contact; mx, maxilla; mx c, maxilla contact; po c, postorbital contact; pop, postorbital process of jugal; qj c, quadratojugal contact. Scale bars in A-B, E-F equal $2 \mathrm{~cm}$; scale bar in C-D equals $3 \mathrm{~cm}$. 
A

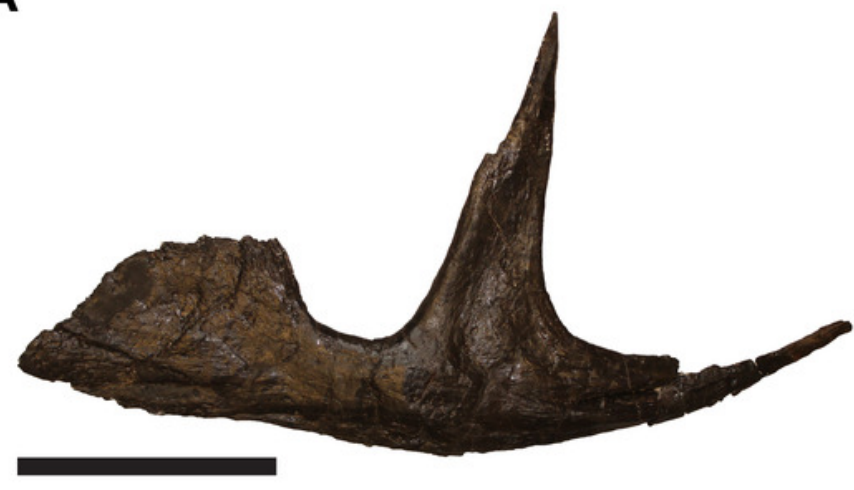

C

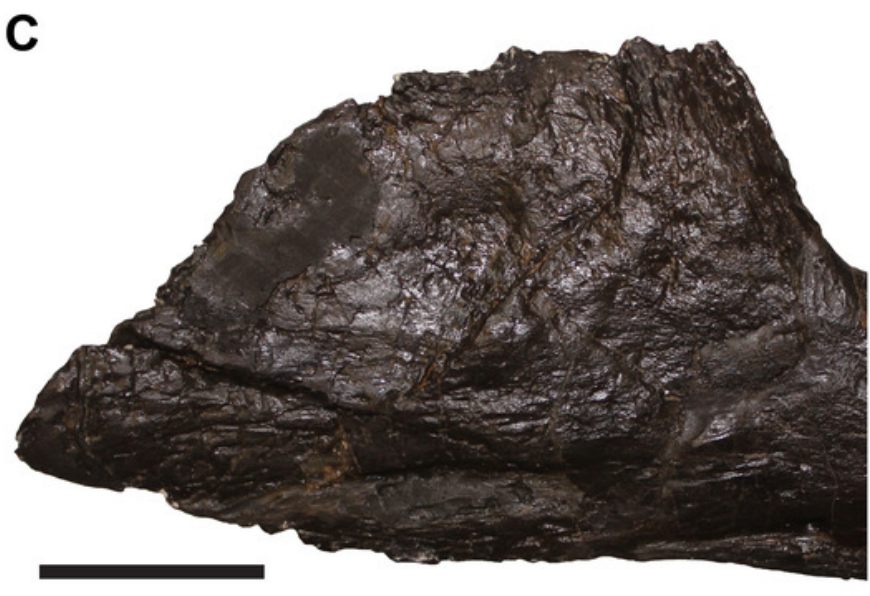

$\mathbf{E}$

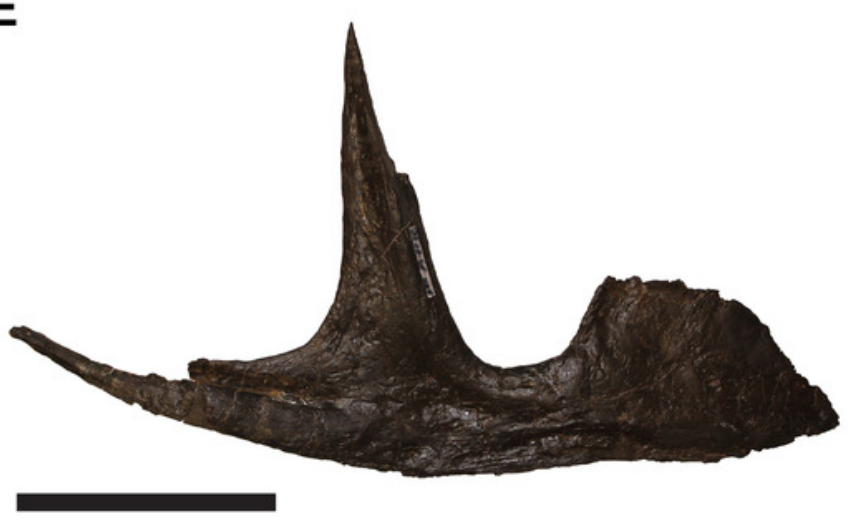

B

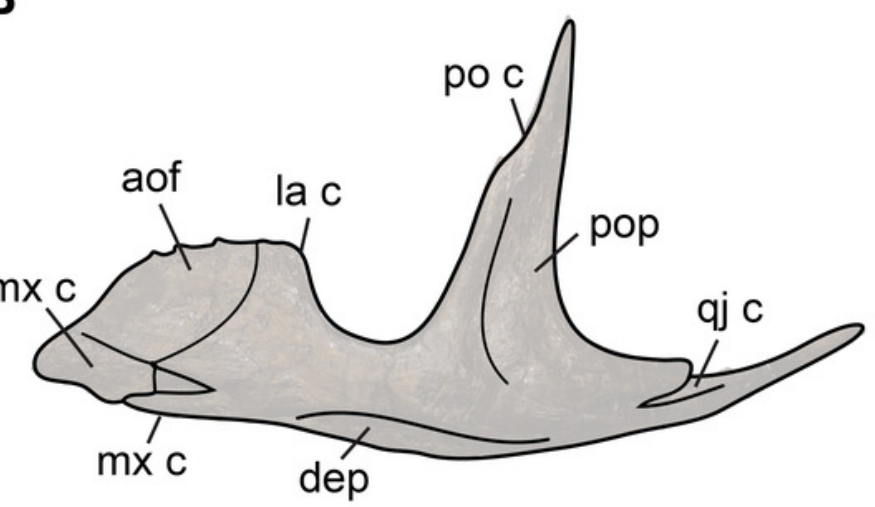

D

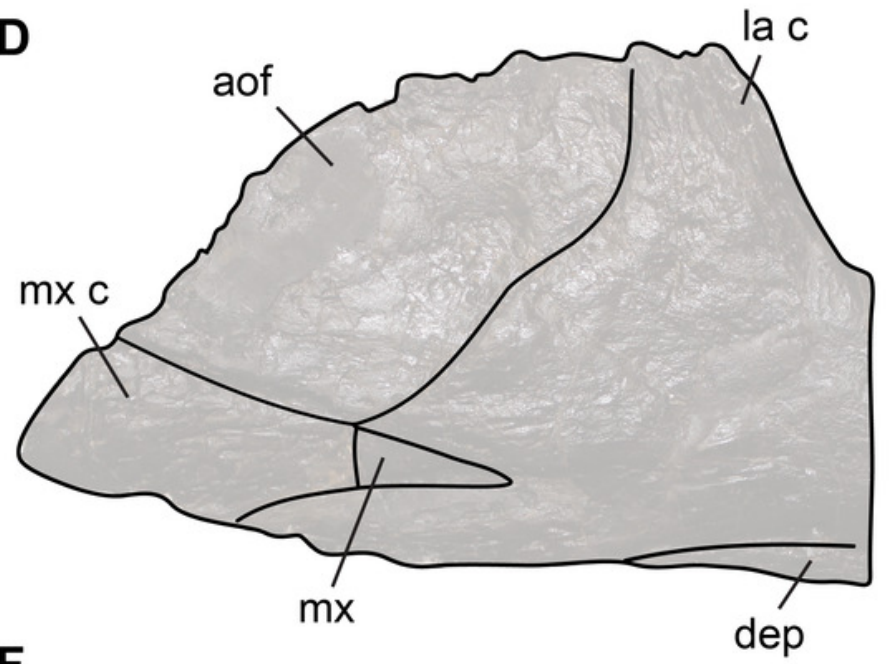

$\mathbf{F}$

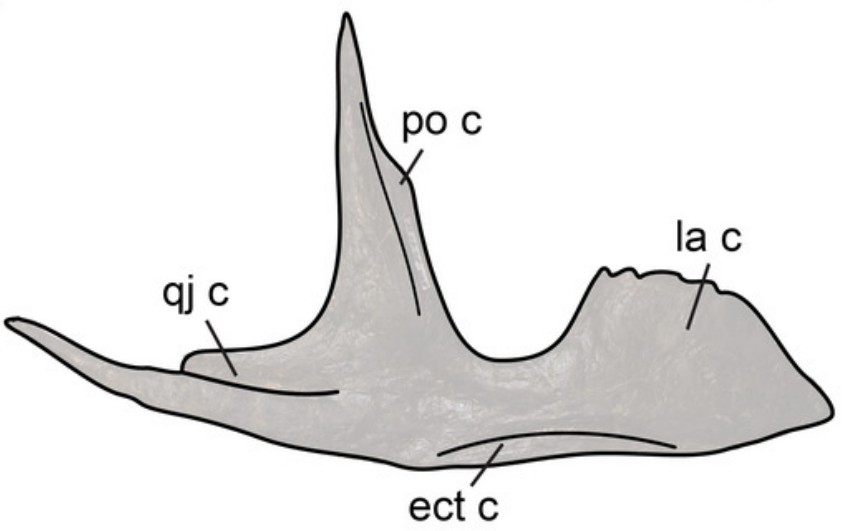




\section{Figure 4}

Jugal pneumatisation in Allosaurus fragilis.

(A) left jugal UMNH VP 8973 in lateral view and with close-up on broken anterior process, revealing pneumatic recess. (B) UMNH VP 8974 in lateral view and with close-up on broken anterior process, revealing pneumatic recess. (C) right jugal UMNH VP 9085 in lateral view and anterolateral close-up of anterior process, showing pneumatic opening in the margin of the antorbital fossa. Note that images in $\mathrm{C}$ are reflected for comparison. Abbreviations: pn, pneumatic recess. Scale bars in close-ups equal $1 \mathrm{~cm}$, scale bars for lateral views equal $3 \mathrm{~cm}$. 


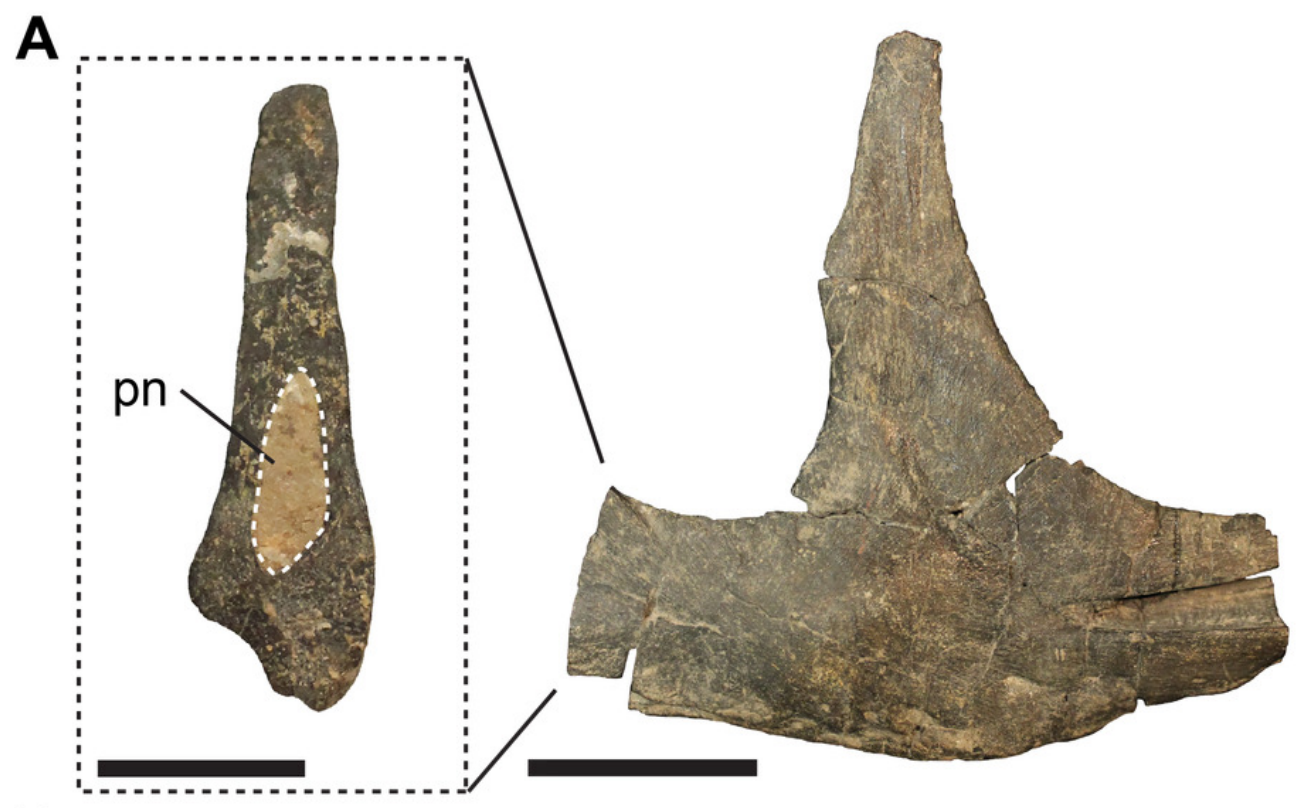

B

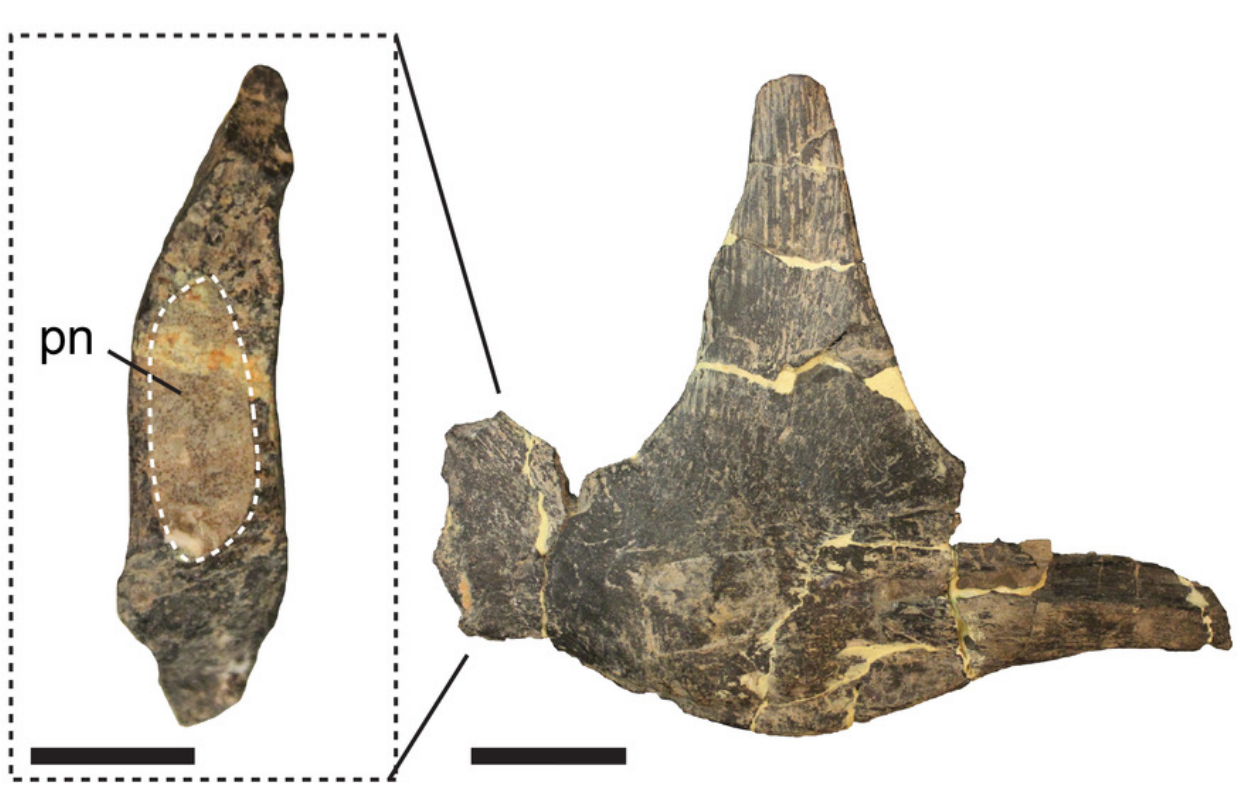

C

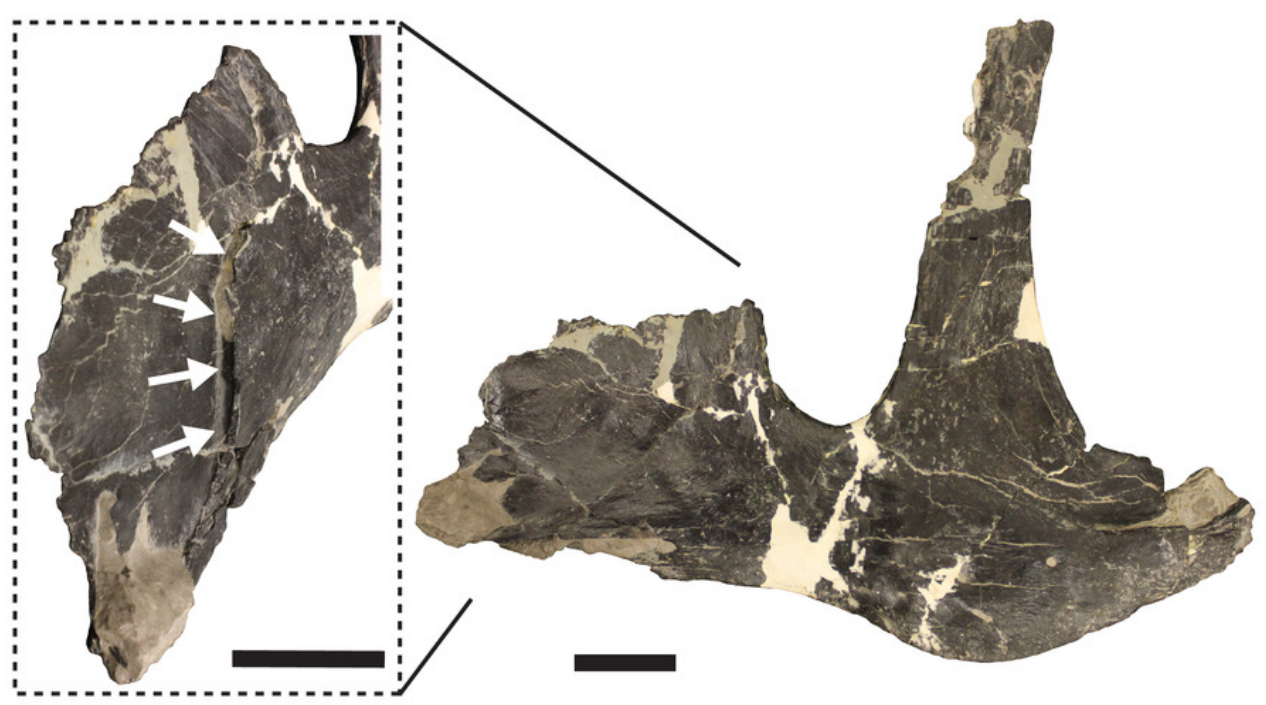

Peer) reviewing PDF | (2019:11:42924:1:1:NEW 27 Dec 2019) 


\section{Figure 5}

Comparison of cheek regions in different specimens of Allosaurus.

(A) left cheek region of DINO 11541, designated holotype of $A$. jimmadseni. (B) left cheek region of MOR 693, A. jimmadseni. (C) reflected right cheek region of DINO 2560 (formerly UUVP 6000), A. fragilis. (D) left cheek region of ML 415, holotype of $A$. europaeus. Abbreviations: j, jugal; la, lacrimal; mx, maxilla. Dashed lines represent bone sutures discussed in the text, and full lines represent the posteroventral margin of the antrobital fossa. Scale bars in B-D equal $10 \mathrm{~cm}$, squares on scale bar in $A$ each equal $1 \mathrm{~cm}$. 
A

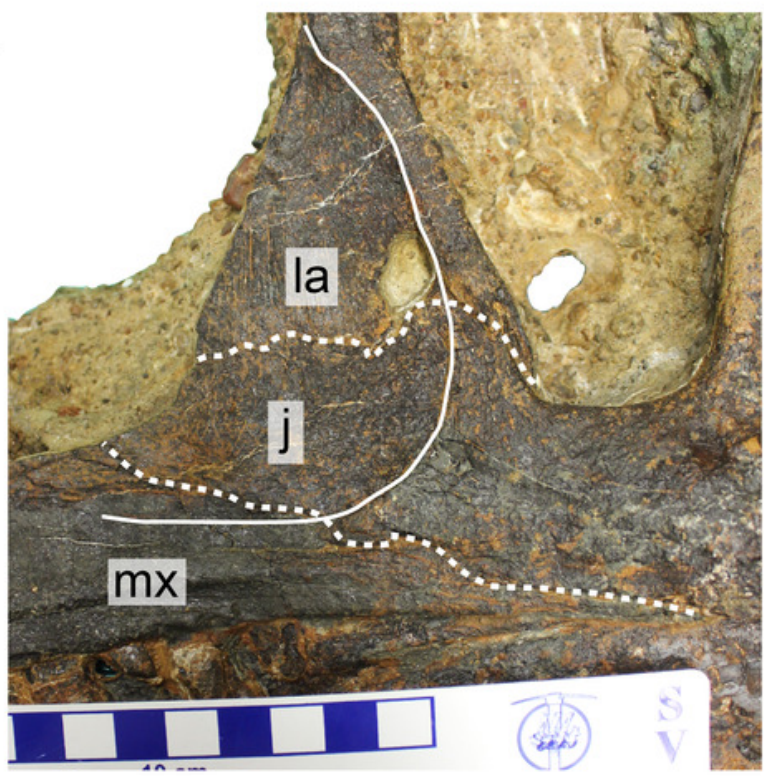

C

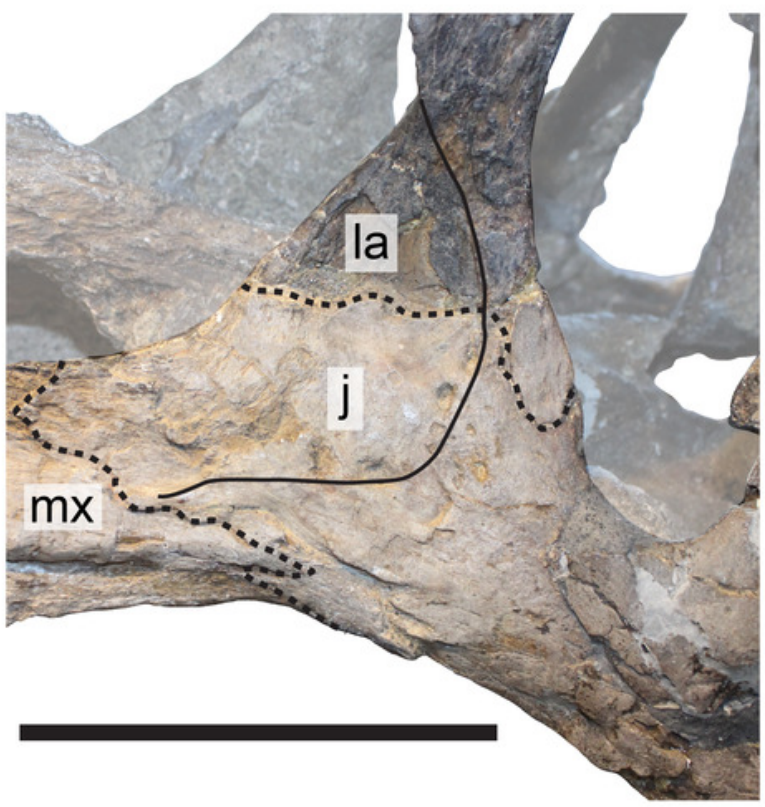

B

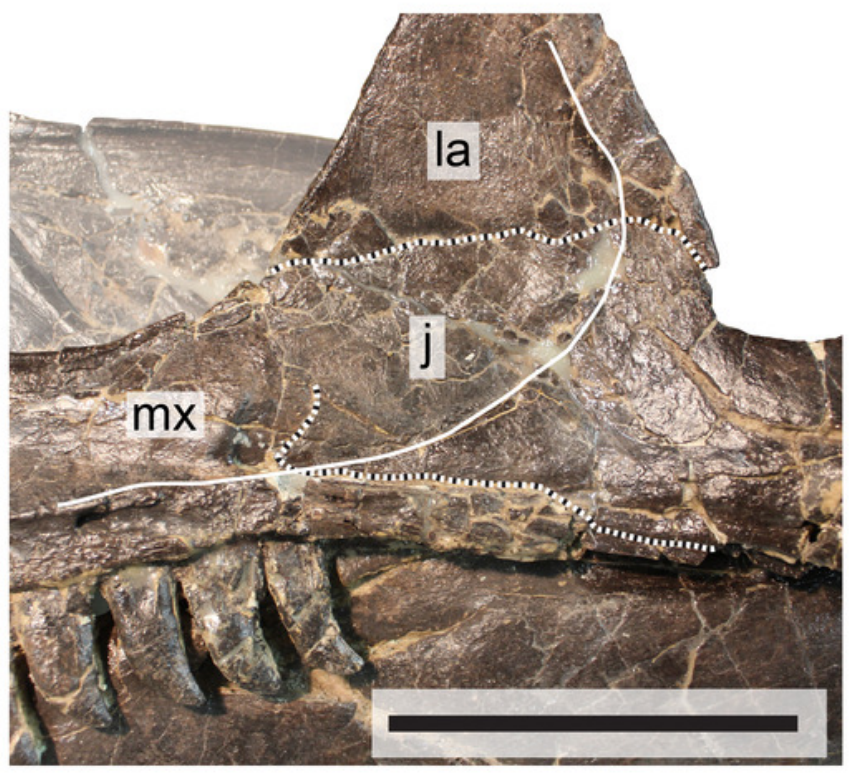

D

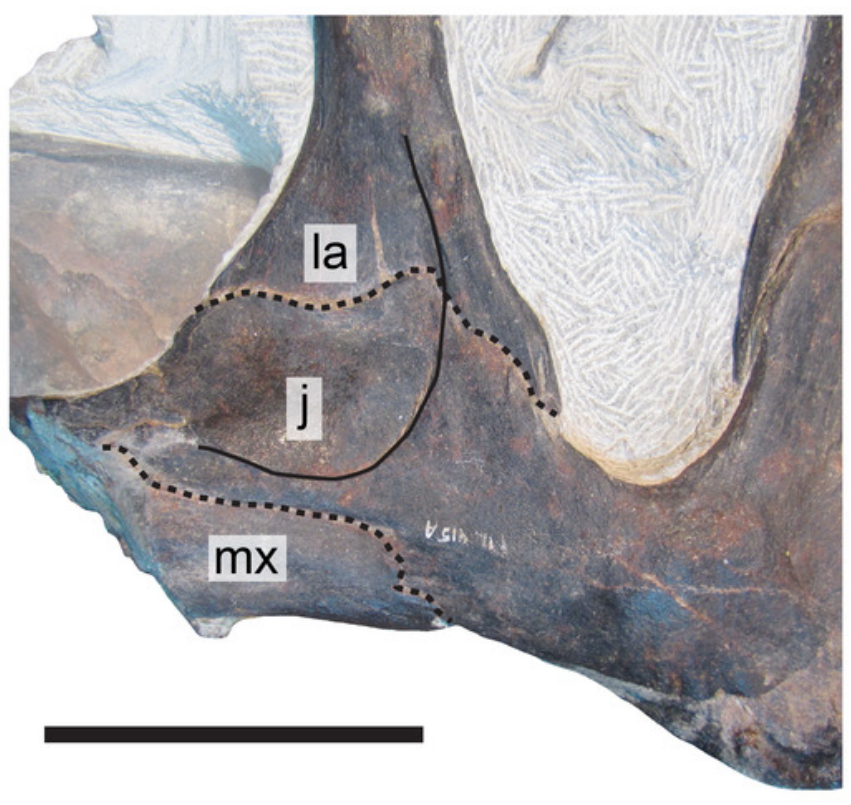


Figure 6

Reconstruction of the skull of Allosaurus, based on MOR 693 (A. jimmadseni).

Note that the jugal participates in the antorbital fenestra, and that the lacrimal overlaps the posterior margin of the anterior jugal process.

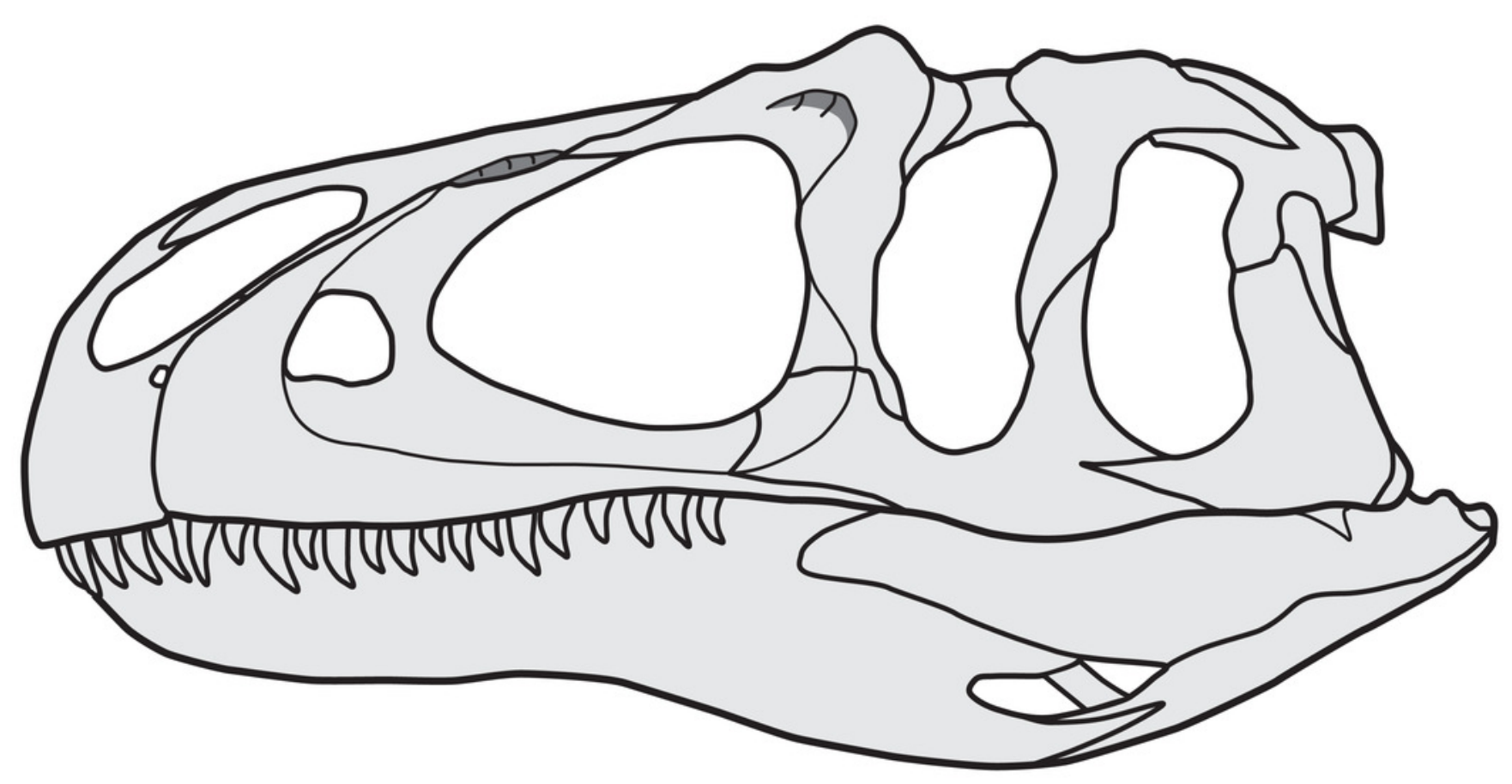

